\title{
Flow tilt angles near forest edges - Part 1: Sonic anemometry
}

\author{
E. Dellwik ${ }^{1}$, J. Mann ${ }^{1}$, and K. S. Larsen ${ }^{2}$ \\ ${ }^{1}$ Wind Energy Division, Ris $\varnothing$ National Laboratory for Sustainable Energy, Technical University of Denmark - DTU, \\ P.O. Box 49, 4000 Roskilde, Denmark \\ ${ }^{2}$ Biosystems Division, Ris $\varnothing$-DTU, Technical University of Denmark - DTU, P.O. Box 49, 4000 Roskilde, Denmark
}

Received: 3 July 2009 - Published in Biogeosciences Discuss.: 12 August 2009

Revised: 18 January 2010 - Accepted: 14 April 2010 - Published: 26 May 2010

\begin{abstract}
An analysis of flow tilt angles from a fetch-limited beech forest site with clearings is presented in the context of vertical advection of carbon dioxide. Flow angles and vertical velocities from two sonic anemometers by different manufacturers were analyzed. Instead of using rotations, where zero-flow angles were assumed for neutral flow, the data was interpreted in relation to upstream and downstream forest edges.

Uncertainties caused by flow distortion, vertical misalignment and limited sampling time (statistical uncertainty) were evaluated and found to be highly significant. Since the attack angle distribution of the wind on the sonic anemometer is a function of atmospheric stratification, an instrumental error caused by imperfect flow distortion correction is also a function of the atmospheric stratification. In addition, it is discussed that the sonic anemometers have temperature dependent off-sets. These features of the investigated sonic anemometers make them unsuitable for measuring vertical velocities over highly turbulent forested terrain. By comparing the sonic anemometer results to that of a conically scanning Doppler lidar (Dellwik et al., 2010b), sonic anemometer accuracy for measuring mean flow tilt angles was estimated to between $2^{\circ}$ and $3^{\circ}$. Use of planar fit algorithms, where the mean vertical velocity is calculated as the difference between the neutral and non-neutral flow, does not solve this problem of low accuracy and is not recommended.
\end{abstract}

Correspondence to: E. Dellwik (ebde@ risoe.dtu.dk)
Because of the large uncertainties caused by flow distortion and vertical alignment, it was only possible to a limited extent to relate sonic anemometer flow tilt angles to upwind forest edges, but the results by the lidar indicated that an internal boundary layer affect flow tilt angles at $21 \mathrm{~m}$ above the forest. This is in accordance with earlier studies at the site.

Since the mean flow tilt angles do not follow the terrain, an estimate of the vertical advection term for near-neutral conditions was calculated using profile measurements of carbon dioxide. The estimated advection term is large, but it is not recommended to include it in the surface carbon balance, unless all terms in the carbon dioxide conservation equation can be precisely estimated.

\section{Introduction}

Eddy covariance measurements, which provide a direct method of measuring turbulent fluxes of carbon to and from the land surface, are the main component in the FluxNet (Baldocchi et al., 2001) network of towers for assessing the terrestrial carbon balance. However, also the mean motion of the air may result in a net flux. This has been recognized in many studies on advection (Lee, 1998; Finnigan, 1999; Baldocchi et al., 2000; Paw U. et al., 2000; Feigenwinter et al., 2004; Aubinet et al., 2005; Vickers and Mahrt, 2006; Mammarella et al., 2007; Heinesch et al., 2007; Feigenwinter et al., 2008; Leuning et al., 2008; Yi et al., 2008; Kutsch et al., 2008).

The advection terms and their contribution to the net exchange of carbon are difficult to assess. For example, after

Published by Copernicus Publications on behalf of the European Geosciences Union. 
considerable experimental effort, Feigenwinter et al. (2008) concluded that the advection terms should not be included for net ecosystem exchange of carbon on an hourly basis, due to excessive scatter. Heinesch et al. (2007) pointed out that the lack of precision of the of mean vertical velocity estimates was one of the main causes of the large uncertainty in the calculated vertical advection term. In a recent study, Leuning et al. (2008) stressed this point by stating a necessary accuracy for the mean vertical velocity of $1 \mathrm{~mm} \mathrm{~s}^{-1}$ in order to include the term at the short timescale. Such precision poses an extreme challenge, especially over forests, where the natural variations due to the turbulent nature of the flow are 100-1000 times greater.

By comparing data from different instruments including both laser (Dellwik et al., 2010b) and sonic anemometry, we try to assess the instrumental precision for determining mean vertical velocities. Using sonic anemometry, vertical velocities can be measured directly. Limitation to the precision of the sonic anemometer comes from flow distortion from the instrument itself (Grelle and Lindroth, 1994), vertical misalignment as well as limited precision of the sonic transducer positioning and a possible temperature dependence of the transducer. The effect of flow distortion correction for sonic anemometry has previously been studied by Heinesch et al. (2007), but is analyzed in more detail here.

Disregarding the instrumental imperfections, the inherent difficulty of assessing a precise mean value from a rapidly varying time series is a challenge when measuring over highroughness surfaces like forests. This limitation to accuracy can be quantified by the statistical or stochastic uncertainty, which is estimated using the vertical velocity variance, the integral length scale, and the length of the time series (Lenschow et al., 1994). In this study, the statistical uncertainty is estimated for varying stability conditions.

The vertical velocity is defined here as the velocity component parallel to the force of gravity. During neutral conditions, for a flat and homogeneous site covered with low vegetation, the mean vertical velocity is zero. In this case, the mean flow follows the terrain and the flow angle during neutral atmospheric stratification is zero. This fact can be used to compensate for the limited instrumental precision of anemometers, by letting the measured neutral flow define the surface over which the mean vertical flow is zero.

For forests, the surface defined by the level of maximum drag in the canopy crown space, which is closely related to the displacement height (Thom, 1971), may or may not be parallel to the ground surface due to variable tree height, thereby adding a level of complexity to the flow. For more complex sites, where either clearings are present, the fetch is limited, or the terrain itself is complex, the neutral flow will not follow neither the ground surface nor the surface defined by the tree crowns, since the flow is still adapting to the inhomogeneities.
With an implicit focus on the instrumental limitations, it has however been common in flux studies to define an empirical reference surface, which in turn defines the direction of the vertical flow component. The definition of this empirical surface is based on the long term mean flow tilt angle, regardless if the flow can be expected to follow the terrain or not. Finnigan (1999) recommended that only measurements taken during near-neutral atmospheric stratification should be used for defining this plane, whereas it also has been common to use all measurements. Once this reference plane has been defined, mean vertical velocities relative to the plane can subsequently be calculated for each measurement run.

Generally, two types of rotation methods have been used for defining a reference plane from the measured wind field: (1) Sinusoidal and offset corrections are applied to measured data, which compensates for a tilt between the underlying surface and the plane defined by the sonic coordinate system as well as an arbitrary off-set (Baldocchi et al., 2000; Paw U. et al., 2000; Feigenwinter et al., 2004). (2) The reference plane is made up of pie-slice-shaped planes, where each sector is intended to be parallel to the underlying surface in the corresponding wind direction. Such an approach has been used by Lee (1998); Mammarella et al. (2008); Feigenwinter et al. (2008); Kutsch et al. (2008) and Yi et al. (2008).

Method 1 corrects for a potential misalignment of the sonic anemometer relative to the underlying surface as well as compensates for an off-set. Method 2 would, as well as remove anemometer misalignment effects and instrumental off-sets, also remove any systematic vertical velocity caused by flow distortion from mast and booms as well as local effects from clearings, roughness changes and non-flat terrain. If a systematic off-set in measured flow angles is caused by the terrain rather than the instrument, the effect of the local terrain of the flow is also removed by method 1 . When applying both method 1 and 2, the planar fit algorithm described by Wilczak et al. (2001) is often used. However, the purpose of their study was to remove the random error on the measured stress.

The above methods were similarly described by Paw U. et al. (2000), who also list a third method which is the one we apply in this study; namely to relate the measured vertical velocities and flow angles to the terrain in the area of the footprint for the measured flux. The main reason for using this method is that at the study site, the flow angles can not be expected to follow the terrain due to both heterogeneities within the forest as well as a limited fetch.

The measurement site used in this study is located in a relatively flat and small beech forest surrounded by agricultural fields near the municipality of Sorø, Denmark. Influence from the fetch limitation has previously been studied at this site (Dellwik and Jensen, 2000, 2005; Mammarella et al., 2008), where the presence of both an internal boundary layer as well as a roughness sublayer were demonstrated and investigated. Vertical velocities in connection with a roughness 
change have previously been studied by Vickers and Mahrt (2006). They investigated the horizontal and vertical advection components in a $300 \mathrm{~m} \times 300 \mathrm{~m}$ large plantation of young pine trees surrounded by taller trees. Compared to their study, the roughness change at our site is larger and of reverse sign (from smooth to rough terrain). Vickers and Mahrt (2006) introduced a fourth method to deduce the mean vertical velocities in an advection study, which is based on careful measurements of the horizontal wind components. Using the continuity equation, the vertical velocity can be deduced from divergence in the horizontal wind field. Compared to methods 1 and 2, no assumption about whether the mean neutral flow angle is equal to zero is necessary. The same method has hence been used by Heinesch et al. (2007) and Leuning et al. (2008). For both studies, a comparison with planar fit estimation of the mean vertical velocity was showing considerable scatter.

Lee (1998) proposed several possible sources for vertical mean velocities, which are caused by large scale temperature-driven atmospheric motions. Near the surface, it was estimated that these temperature-driven vertical velocities are of the order $\mathrm{mm} \mathrm{s}^{-1}$ to $\mathrm{cm} \mathrm{s}^{-1}$. Lee (1998) assumed that flux sites are located in homogeneously vegetated and flat terrain, in which case local effects on the vertical flow would be negligible. By calculating the vertical velocities relative to the defined reference plane, one would therefore directly be able to assess the large-scale driven vertical motions and estimate their impact on the carbon budget.

For the less ideal sites, where carbon dioxide advection studies have taken place, the interpretation of positive or negative flow angles relative to the reference plane is less straight-forward. The estimated vertical velocities can then only represent large scale temperature-driven vertical motions described by Lee (1998), if one assumes that the topography effects and the stability effects can be separated. This assumption is problematic especially over forested terrain, where - in addition to the relatively large natural variability of a forest - specific canopy-flow features such as flow separation already at moderately sloped forested hills (Sogachev et al., 2004; Belcher and Hunt, 1998) and separation of the above/below canopy flow (Smith et al., 1972; Belcher et al., 2008) are typically expected to vary with atmospheric stability.

The aim of this paper is to understand the most crucial uncertainties related to measured vertical velocities, the possible effect of inhomogeneity on the vertical velocities and what the implication is for determining the vertical advection term in the carbon dioxide mass conservation equation at sites influenced by surface inhomogeneities.

\section{Sonic anemometer accuracy}

In principle, the sonic anemometer is a calibration-free instrument where the measurement principle is based on the accurate time-of-flight recordings of a sound pulse. The accuracy of the instrument is however limited by how the instrument structure modifies the flow. This modification of the wind field is commonly termed flow distortion. Grelle and Lindroth (1994) give a good overview of the early work on sonic anemometry flow distortion. In order to quantify the flow distortion effects, wind tunnel studies of sonic anemometers have been performed (Grelle and Lindroth, 1994; van der Molen et al., 2004; Högström and Smedman, 2004). Grelle and Lindroth (1994) showed that the influence on azimuth angle for a Solent sonic anemometer (Gill Instruments Ltd.) was great compared to the effect of tilting the instrument within a $\left[-10^{\circ}, 10^{\circ}\right]$ interval from horizontal. They also found that the flow distortion was dependent on wind speed.

Gash and Dolman (2003) reported that over high roughness areas, such as forests, eddies hit the surface at a much steeper angle than over low-roughness terrain, and that limited calibration had a large impact on the measurement of fluxes. Following the work of Gash and Dolman (2003), van der Molen et al. (2004) developed a new sonic calibration scheme based on wind tunnel data for attack angles up to $\pm 90^{\circ}$ for Solent R2 and R3 sonic anemometers, and it was reported that the variation in azimuthal flow distortion was small compared to the effect of high tilt angles, where reduction in speed up to $60 \%$ was recorded. This correction scheme was numerically improved by Nakai et al. (2006) to account more rigorously for the fact that the angle of attack, which is calculated from the measured wind vectors, also contains an error. Apart from this numerical improvement of the correction scheme, the Nakai et al. study also included an updated correction for near-zero flow angles. The effect of the sonic calibration presented in van der Molen et al. (2004) has to some extent previously been examined by Heinesch et al. (2007), but these effects have otherwise been ignored.

Högström and Smedman (2004) also tested the Solent anemometer in the wind tunnel and concluded that the effects of flow distortion were different in the wind tunnel and in the real atmosphere.

The sonic anemometer manufacturers may provide calibration schemes for flow distortion. This is the case for the Solent anemometers by Gill Instruments and the USA1 sonic by Metek GmbH., which are the sonic anemometers in focus for this study, where wind-tunnel based correction scheme are built-in to directly correct the sampled data. The sonic anemometers by Gill are calibrated individually in a wind tunnel to an accuracy of 1.5-3\% (1012-PS-0014, Gill Instruments, 1990), but only for wind attack angles up to $10^{\circ}$ relative to the horizontal. Some details of this calibration procedure can be found in Grelle and Lindroth (1994). It is further not recommended to use for attack angles beyond $30^{\circ}$ relative to the horizontal. However, Grelle and Lindroth (1994) found that applying the correction by the manufacturer actually increased the flow distortion effects. The resulting tilt angle error after applying the correction by the manufacturer was for some azimuth directions as large as 


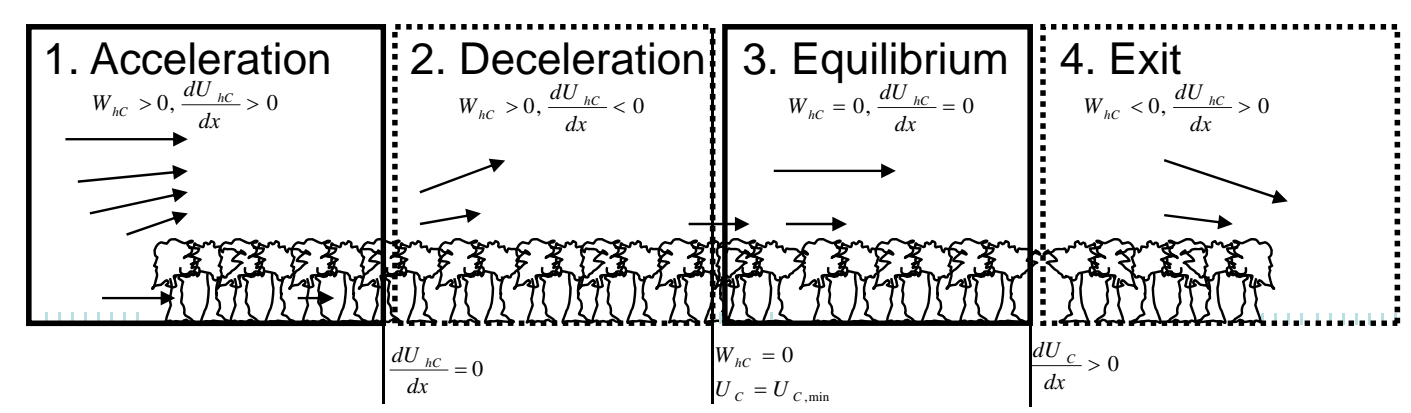

Fig. 1. Sketch of flow downstream of a forest edge.

$2^{\circ}$. In combination with the reported wind speed dependence mentioned above, this result seriously questions the ability of the Solent anemometer to accurately measure flow tilt angles.

The USA-1 Basic sonic anemometer has a built-in calibration for flow distortion at zero-angle of attack. Metek $\mathrm{GmbH}$. further provides a correction scheme for the instrument in the interval of $-50^{\circ}$ to $+45^{\circ}$ angle of attack on demand. This correction, which is built-in for another version of the same instrument, is a Fourier series approximation to the instrumental flow distortion measured in a wind tunnel, and it is a function of wind direction and angle of attack on the sonic anemometer. It has to be applied to the raw data, such that the corrected data in this study are first de-corrected for the built in correction and then re-corrected with the $-50^{\circ}$ to $+45^{\circ}$ correction. For attack angles outside the calibration interval, the end point values are applied.

Another issue regarding sonic anemometry accuracy concerns the temperature dependency of the transducers. For example, the accuracy of the Gill anemometers of 1.5-3\% is only valid for temperatures between $5{ }^{\circ} \mathrm{C}$ and $35^{\circ} \mathrm{C}$. Depending on the temperature response of the individual transducers of the Metek USA-1 three paths, it was estimated that a temperature driven off-set in the vertical velocity could in the worst case scenario vary as much as $0.10 \mathrm{~ms}^{-1}$ over a temperature range of -20 to $+30^{\circ} \mathrm{C}$, while the horizontal wind speed is not affected at all (Hans-Jürgen Kirtzel, Metek GmbH., personal communication, 2010). Wind tunnel investigations of the Solent R2 at Ris $\varnothing$-DTU during the 1990ies, also pointed to significant temperature effects on $W$ (Niels Gylling Mortensen, Ris $\emptyset$-DTU, personal communication, 2010).

\section{Theory}

\subsection{Expected effect of forest edge on vertical velocities}

We hypothesize, that the atmospheric flow encountering a perfect two-dimensional fetch-limited forest may be described by the following phases (Fig. 1):

(1) Edge phase: At the forest edge, the mean flow is dominated by the physical effect of the edge, which accelerates the flow above the canopy and decelerates the flow within the canopy. Both above and below the crowns, the mean vertical velocity $W$ is positive. Above the canopy $W$ decreases with height and within the canopy $W$ increases with height.

(2) Deceleration phase above the canopy: At canopy height $h_{C}$, the mean wind speed $U$ starts decelerating from the point where $\left.\frac{d U}{d x}\right|_{h_{C}}=0$, due to the high roughness of the forest. The mean wind speed in the canopy $\left(U_{C}\right)$ keeps decelerating and reaches its minimum value $U_{C, \min }$ at the end of phase 2. In the deceleration phase, $W$ is, due to continuity, slightly positive within the canopy. Above the canopy $W$ is small but positive and increases with height until it eventually returns to zero. The end of phase 2 is defined by $W\left(h_{C}\right)=0$.

(3) Equilibrium phase: This phase starts at the point where $W\left(h_{C}\right)=0$ again. There is no net vertical motion between the below-canopy and above canopy regions as the below canopy flow and the above canopy flow are in equilibrium. The internal boundary/equilibrium layer is deep and effects from the edge are of no importance.

(4) Exit phase: The starting point of the exit phase occurs where the flow in the canopy starts accelerating $\frac{d U_{C}}{d x}>0$, due to the presence of the downstream edge. At canopy height, $W$ turns negative.

Compared to the edge flow regimes defined by Belcher et al. (2003) for a forest of limited horizontal extent, this subdivision of the flow phases downstream of an edge is more focused on the flow angles and builds heavily on the continuity argument.

Experimental support for the existence of phases 1 and 2 was presented by Irvine et al. (1997), who reported positive flow angles near the edge of a Sitka spruce plantation, a slight speed-up of the flow at the edge for the height $2 h_{C}$ at $x=3.5 h_{C}$ and flow deceleration at $h_{C}$ for $x<14.5 h_{C}$. The forest edge wind-tunnel study by Morse et al. (2002) showed positive flow angles above the canopy for $x<5-7 \mathrm{~h}_{C}$ and negative vertical velocities from $x>7 h_{C}$ for a forest extent of $12 h_{C}$. 
Flow tilt angles from a Large Eddy Simulation (LES) model study by Yang et al. (2006) showed only positive flow angles for the interval $-3 \mathrm{~h} C<x<11 \mathrm{~h}_{C}$ and negative flow angles were present from $x>11 \mathrm{~h}_{C}$ above the canopy, where the trailing forest edge was located at $x=19 \mathrm{~h}_{C}$. In the LES study by Dupont and Brunet (2008), which modeled a forest-clearing-forest configuration, the effect of varying Leaf Area Index (LAI) and Leaf Area Density (LAD) profiles was investigated. Generally, the flow above the high LAI canopy showed faster adaptation to the forest. The change from positive to negative flow angles occurred in the interval $10 h_{C}<x<15 h_{C}$ depending on LAI and LAD for a forest of $20 h_{C}$ extension. In the LES study by Cassiani et al. (2008), a LAI variation showed similar effects on mean flow angles as in the study by Dupont and Brunet (2008). Contrary to the other studies, Cassiani et al. (2008) also found a recirculation zone within the canopy at high LAI.

\subsection{Statistical uncertainty of the mean vertical velocity}

The relationship between averaging time $T$ and statistical uncertainty expressed as the variance of mean vertical velocity $\sigma_{W_{T}}^{2}$ can be stated from e.g. Lenschow et al. (1994) as follows

$T=2 \frac{\sigma_{w}^{2}}{\sigma_{W_{T}}^{2}} \cdot \mathcal{T}$

Here, $\sigma_{w}^{2}$ is the variance of the instantaneous vertical wind speed $w$ and $\mathcal{T}$ is the integral time scale of the vertical velocity fluctuations. In order to explicitly calculate $\sigma_{W_{T}}$, Eq. (1) can be re-arranged to

$\sigma_{W_{T}}=\sigma_{w} \sqrt{\frac{2 \mathcal{T}}{T}}$

From Eq. (2), the uncertainty of the mean flow angle $\alpha$ can be derived as (Panofsky and Dutton, 1984):

$\sigma_{\alpha_{T}} \approx \frac{\sigma_{W_{T}}}{U}$

where the approximation for small angles $\tan \alpha \approx \alpha$ has been applied. An alternative derivation which takes the influence of higher order moments into account is given by Gash and Dolman (2003).

For the calculations in this study, $\mathcal{T}$ was calculated from a least square fit of the power spectral density of the instantaneous vertical velocity measurements to the Cauchy-Lorentz spectrum

$\Phi_{w}(\omega)=\frac{A}{1+\omega^{2} \mathcal{T}^{2}}$,

where $A$ is a constant, $\omega$ is the wave number and $\Phi_{w}(\omega)$ is the Fourier transform of the autocorrelation function (Lenschow et al., 1994).

\section{Materials and methods}

\subsection{Site}

The vegetation at the Sorø site $\left(55^{\circ} 29^{\prime} 9.5^{\prime \prime} \mathrm{N} 11^{\circ} 38^{\prime} 40.5^{\prime \prime} \mathrm{E}\right)$ on the island of Zealand, Denmark, consists predominantly of an 85 year old beech forest with a rather uniform height of about $26-27 \mathrm{~m}$. The standard setup at the $57 \mathrm{~m}$ tall mast and $25 \mathrm{~m}$ tall scaffolding tower $8 \mathrm{~m}$ North of the mast, as well as general site information, can be found in Pilegaard et al. (2003). Information about fetch limitation and how it influences the wind and temperature flux-profile relationship at the mast position was discussed in Dellwik and Jensen (2005).

For the current focus on flow angles and vertical velocities in relation to the terrain, a terrain map is presented in Fig. 2 (left) where the full line shows the outline of the forest. The forest is located on almost flat terrain with an inclination of $\approx 0.5^{\circ}$ from the SW to the NE. Height profiles from aerial photography taken in 1995 (Dellwik and Jensen, 2005 ) indicated that the local variation of canopy height is much greater than the $\approx 0.5^{\circ}$ over distances of $\approx 10 \mathrm{~m}$. However, over longer distances, the canopy height may compensate for the slope, such that a general direction of the canopy top inclination is hardly distinguishable. In Fig. 2 (right), an aerial photograph from 2006 is shown (courtesy to Google Earth). The complex nature of the vegetation cover is clearly visible. The stated distances to clearings, inhomogeneous surface cover and forest edges in the figure caption were assessed using Google Earth, as the distance from the mast to the first step change in vegetation height. The directions from the mast to the clearings/change of vegetation are approximate, given the relatively large transversal extension of the terrain features.

The Leaf Area Index (LAI) at the Sorø beech forest site shows a strong intra-annual pattern, characterized by a low value during winter, a sharp transition to a high leaf area index around May 1st and a slow descent back to winter values in October-November. Between the beginning of June to the end of August, LAI is nearly constant and approximately $5 \mathrm{~m}^{2} \mathrm{~m}^{-2}$. During winter, LAI has been measured to approximately $1 \mathrm{~m}^{2} \mathrm{~m}^{-2}$. The measurements were taken with a LAI-2000 PCA (Li-Cor, Nebraska, USA).

The displacement height $d$ is estimated to be $21 \mathrm{~m}$ based on earlier analysis of the wind profile (Dellwik and Jensen, 2005) as well as an estimate of forest height to approximately 26-27 m.

\subsection{Instrumentation and data processing}

Measurments from a setup with two sonic anemometers at the Sorø mast were analyzed (Table 1). These were the eddy-covariance Solent R2 sonic anemomter at $43 \mathrm{~m}$ (Gill Instruments Ltd.) and a USA-1 Basic (Metek GmbH) at $31.5 \mathrm{~m}$ height. Both the Solent R2 and USA-1 sonic heads 


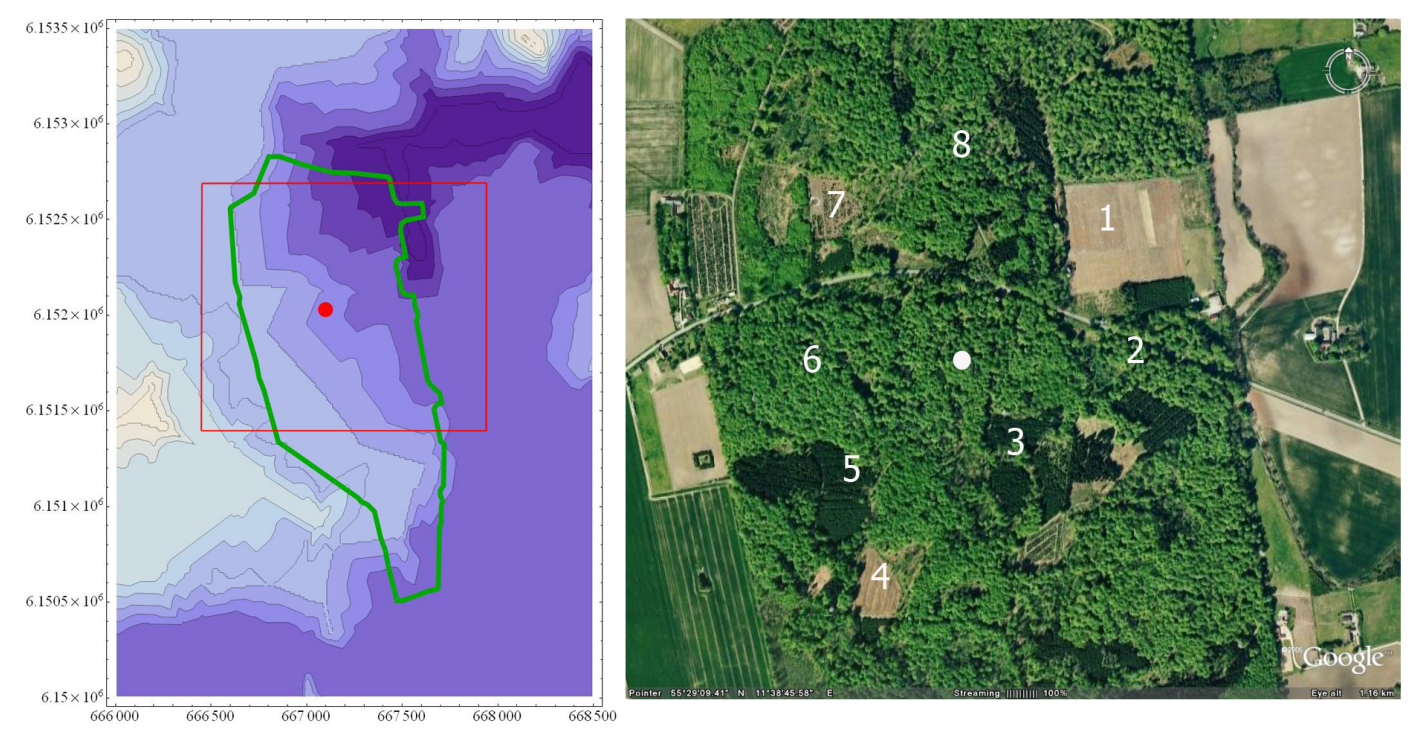

Fig. 2. Map and aerial photography of the Sor $\varnothing$ site. The height contours (left pane) signify $2 \mathrm{~m}$ height differences and the red box outlines the area in the photograph. The numbers in the right pane refer to the following features: (1) $8 h_{C}$ to a large clearing in the direction of $\approx 60^{\circ}$ from the mast, (2) Narrow strip of $17 h_{C}$ homogeneous beech forest to forest edge in $\approx 90^{\circ}$, (3) $4 h_{C}$ to a $15 \mathrm{~m}$ tall plantation of Norway Spruce in $155^{\circ}$, (4) $13 h_{C}$ to a clearing in $200^{\circ}$, (5) $10 h_{C}$ to another $15 \mathrm{~m}$ tall plantation of Norway spruce in $225^{\circ}$, (6) $17 h_{C}$ to the forest edge in $260^{\circ}$, (7) $9 h_{C}$ to a clearing with younger beech of 5-6 m height in $315^{\circ}$ and finally (8) $26 h_{C}$ to the forest edge in $360^{\circ}$. The white dot corresponds to the location of the mast.

are designed with the acoustical transducers on a vertical rod. The rod of the Gill sonic is $52 \mathrm{~cm}$ and the sonic head has the dimensions $24 \times 23 \mathrm{~cm}$ including supporting rods. The sound path is $14.9 \mathrm{~cm}$. The USA-1 sonic head is slightly larger with the dimensions $32 \times 24 \mathrm{~cm}$ with no supporting rods and the vertical bar is $47 \mathrm{~cm}$. The length of the sound path is $17.5 \mathrm{~cm}$.

Both van der Molen et al. (2004) and Nakai et al. (2006) provide add-on corrections for the Solent R2 design for all angle of attacks that can be downloaded from personal home pages listed in Nakai et al. (2006). These schemes were applied to the measured data. The USA-1 sonic anemometer was corrected with the $-50^{\circ}$ to $+45^{\circ}$ correction supplied by the manufacturer, where the built-in correction for horizontal flow was first removed.

For the eddy-covariance system at Sorø, the Solent 1012 R2 at 43 m height and a LiCor 7000 (Li-Cor, Nebraska, USA) were employed. The measurement record of carbon dioxide and water vapor fluxes started in 1996 and has run continuously since then. A profile system for measurement of carbon dioxide was operational from the spring of 2007 after a longer break. The carbon dioxide concentrations were measured at $0.1,0.5,1,5,15,30$ and $41 \mathrm{~m}$ above the soil surface via a series of Teflon tubes (inner diameter $4.8 \mathrm{~mm}$ ) installed on the mast. One height at a time was sampled for $90 \mathrm{~s}$ and the different heights were sampled in a step-wise order to ensure that all heights were measured at least twice per $30 \mathrm{~min}$ interval. The carbon dioxide concentrations were analyzed on an ADC-7000 infra-red gas analyzer, see Pilegaard et al. (2003) for more details.
Data were analyzed for both the summer and winter period (see Table 1). The limits of the periods were decided either by strict constancy of leaf area or availability of data from both sonic anemometers.

The data were block averaged over $30 \mathrm{~min}$ intervals and the sonic data were calculated using only one sonic rotation (alignment with the mean wind direction). For the heat, carbon dioxide and momentum fluxes, the difference between this single rotation scheme and the more traditional double rotation McMillen (1988) was assessed and found negligible.

Initially, we assumed that the measured vertical data represent the flow parallel to the acceleration of gravity and perpendicular to the underlying surface. The real deviations and their possible effect on the interpretation of the measured data is discussed in Sect. 6.

For all neutral data it was required that $\left|\frac{z_{m}-d}{L}\right|<0.1$ and the $U_{z_{m}}>3 \mathrm{~ms}^{-1}$, where $z_{m}=43 \mathrm{~m}$ is the measurement height and $L$ the Monin-Obukhov length. Especially during the winter time, the Metek sonic showed irregular instrumental failures mostly due to precipitation and further screening was necessary. Additional requirements were $U_{43 \mathrm{~m}}>U_{31 \mathrm{~m}}$, $\sigma_{w}^{2}>0.03 \mathrm{~m}^{2} \mathrm{~s}^{-2}$ and finally less than 10 samples, i.e. halfhour runs, were removed by requiring that the mean flow tilt angles was less than 6 degrees. Data not fulfilling this last criterion were typically taken immediately before or after instrumental failures. The winter dataset contained 53 cases of apparent negative shear, where the dominating part was associated with precipitation. This procedure 
Table 1. Overview of experiments used for instrument intercomparison.

\begin{tabular}{lll}
\hline Dataset & Duration of experiment & Measurement height (m) \\
\hline Sorø "summer" & 1 Jun 2005-31 Aug 2005 & 43 m Gill R2, 31.5 m Metek USA-1 \\
Sorø "winter" & 18 Jan 2005-28 Apr 2005 & 43 m Gill R2, 31.5 m Metek USA-1 \\
\hline
\end{tabular}

left 2150 near-neutral samples for the summer period and 3347 samples for the winter period.

For summer data, stability effects were examined, both in relation to the statistical uncertainty analysis (Eq. 2) and for interpreting the dependence on the terrain. In these analyses, it was required that $\left(z_{m}-d\right) / L<-0.1$ (unstable) or $\left(z_{m}-d\right) / L>0.1$ (stable), $U_{43 \mathrm{~m}}>U_{31 \mathrm{~m}}$ and $U_{z_{m}}>1 \mathrm{~ms}^{-1}$ (both unstable and stable). Samples with $U_{43 \mathrm{~m}}<1 \mathrm{~ms}^{-1}$ occurred about $2 \%$ of the time both for the summer and the winter datasets. Negative shear with $U_{43 \mathrm{~m}}>1 \mathrm{~ms}^{-1}$ occurred for 10 samples during the summer $(0.2 \%$ of the time) and was associated with low-wind instationary flow. The stable and unstable subsets were much smaller than the near-neutral subset, with 738 stable samples and 238 unstable samples.

A subset of the summer data was selected for $10 \mathrm{~Hz}$ time series analysis. Here the criteria were sharpened as follows: wind directions should be in the interval $\left[250^{\circ}, 280^{\circ}\right]$ to provide a uniform fetch, $\left|\frac{z_{m}-d}{L}\right|<0.01$ (near-neutral subset), $-0.5<\frac{z_{m}-d}{L}<-0.1$ (unstable subset), $0.1<\frac{z_{m}-d}{L}<0.5$ (stable subset). These sharpened stability criteria left 50 nearneutral, 45 stable and 19 unstable of $30 \mathrm{~min}$ averaged measurement runs.

\section{Results}

\subsection{Effect of sonic flow angles and flow distortion corrections}

In order to assess the importance of the flow distortion correction, the attack angle probability density function ("pdf") on the Solent R2 sonic was calculated as $\arctan \frac{w}{\sqrt{u^{2}+v^{2}}}$, where $v$ denotes the transversal wind component (Fig. 3, left). Similarly, the pdf for vertical wind speeds was evaluated using $10 \mathrm{~Hz}$ data (Fig. 3, right).

The attack angle distribution during unstable atmospheric stratification was wider than for the neutral subset, which in turn was wider than the stable subset. For the neutral subset, attack angles outside the $\pm 10^{\circ}$ interval (within which the manufacturer guarantees a certain accuracy) from the horizontal occur $31 \%$ of the time, and $38 \%$ and $18 \%$ of the time for the unstable and stable subset, respectively. Attack angles outside the $\pm 30^{\circ}$ interval occurs between $0.6 \%$ (stable subset), $2.2 \%$ (near-neutral) and $4.2 \%$ (unstable subset) of the time. The pdf of the attack angles was non-symmetrical around zero for all stability classes.
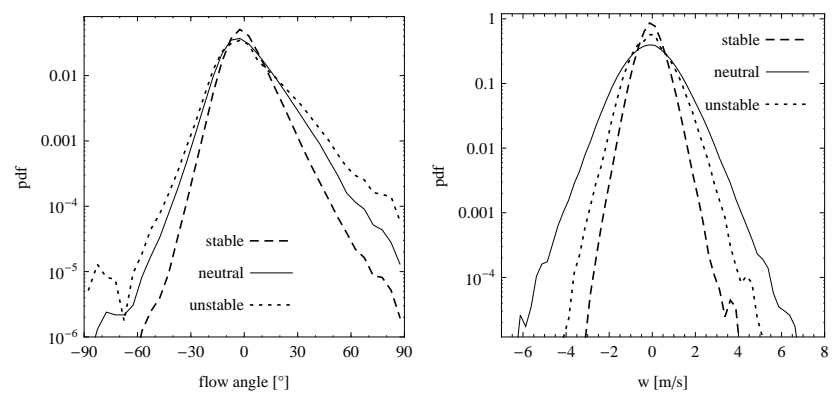

Fig. 3. Probability density of attack angle on sonic anemometer (left) and vertical velocities for three atmospheric stability subsets (right) based on Solent R2 $10 \mathrm{~Hz}$ data.

The maximum values of $w$ were generally higher during near-neutral conditions than during stable/unstable atmospheric stratification and the occurrence of vertical wind greater than $2 \mathrm{~ms}^{-1}$ varies between $0.1 \%$ (stable subset) to $5.5 \%$ (neutral subset). The maximum measured value of $w$ for this $10 \mathrm{~Hz}$ subset of summer data was around $7 \mathrm{~ms}^{-1}$.

The effects of the sonic flow distortion corrections are shown in Fig. 4, where mean diurnal courses of $W$ are presented (top). For this analysis, all data with $U_{43 \mathrm{~m}}>1 \mathrm{~ms}^{-1}$ was used. The flow distortion correction led to a different diurnal course and reverse sign for the Solent R2 measurements, whereas the weaker diurnal course for the USA-1 was preserved. The correction was greater during the day than during night, partly because of the generally higher wind speed during the day. For the Solent R2 anemometer, the "corr 1" and "corr 2" corrections correspond to the corrections presented by van der Molen et al. (2004) and Nakai et al. (2006). Both flow distortion corrections for the Solent sonic led to a negative shift of vertical velocities, whereas the flow distortion correction for the USA-1 resulted in a positive shift of the vertical velocities. The Solent vertical velocities were changed on average $0.09 \mathrm{~ms}^{-1}$ and the USA-1 signals was changed $0.013 \mathrm{~ms}^{-1}$. Mean flow angles were calculated as $\arctan (W / U)$, and here the effect of the flow distortion correction was on average $1.3^{\circ}$ and $0.3^{\circ}$ for the Solent R2 (both schemes) and USA-1 sonic respectively (Fig. 4, bottom). 

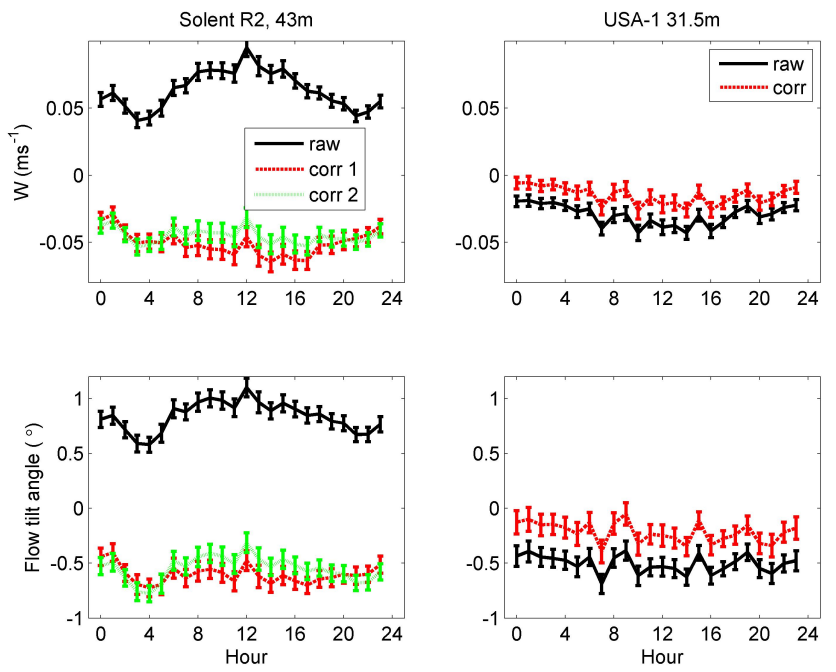

Fig. 4. Effect of flow distortion corrections on mean daily courses of mean vertical velocities and flow tilt angles for all wind directions and stabilities.

Table 2. Vertical wind parameters evaluated for $T=1800 \mathrm{~s}$ from the Solent R2 $10 \mathrm{~Hz}$ data for westerly wind directions. $\mathcal{L}=U \mathcal{T}$ (see Eq. 4) is the integral length scale.

\begin{tabular}{lccrcc}
\hline Subset & $<W>\left(\mathrm{ms}^{-1}\right)$ & $\frac{\sigma_{w}}{U}(-)$ & $\mathcal{L}(\mathrm{m})$ & $\sigma_{W_{T}}\left(\mathrm{~ms}^{-1}\right)$ & $\sigma_{\alpha_{T}}\left({ }^{\circ}\right)$ \\
\hline Near-neutral & -0.10 & 0.21 & 10.9 & 0.05 & 0.6 \\
Stable & -0.06 & 0.15 & 6.8 & 0.02 & 0.4 \\
Unstable & -0.06 & 0.24 & 15.7 & 0.06 & 1.0 \\
\hline
\end{tabular}

After the corrections, the mean diurnal course of $W$ by the two sonic anemometers were in better agreement.

\subsection{Statistical uncertainty}

For the $10 \mathrm{~Hz}$ data from the Solent $\mathrm{R} 2$, the integral time scale $\mathcal{T}$ was calculated using Eq. (4). These values, in combination with measured $\sigma_{w}$, were used to estimate the statistical uncertainties $\sigma_{W_{T}}$ and $\sigma_{\alpha}$ from Eq. (2) for $T=1800 \mathrm{~s}$ (Table 2). The statistical uncertainty $\sigma_{W_{T}}$ was of the same order of magnitude as the measured mean value of the vertical velocity $W$. There was a clear dependence on atmospheric stability with the greatest uncertainties associated with the unstable subset.

\subsection{Analysis of flow tilt angles relative to the terrain}

In order to understand the possible terrain effect on the sonic measurements, the flow angles were analyzed as a function of wind direction for the two sonic anemometers, both for the winter and the summer period. In Fig. 5, the results for nearneutral data is shown. Flow distortion corrections were applied and for the Solent R2 sonic, the numerically improved version of the correction was used ("corr 2").
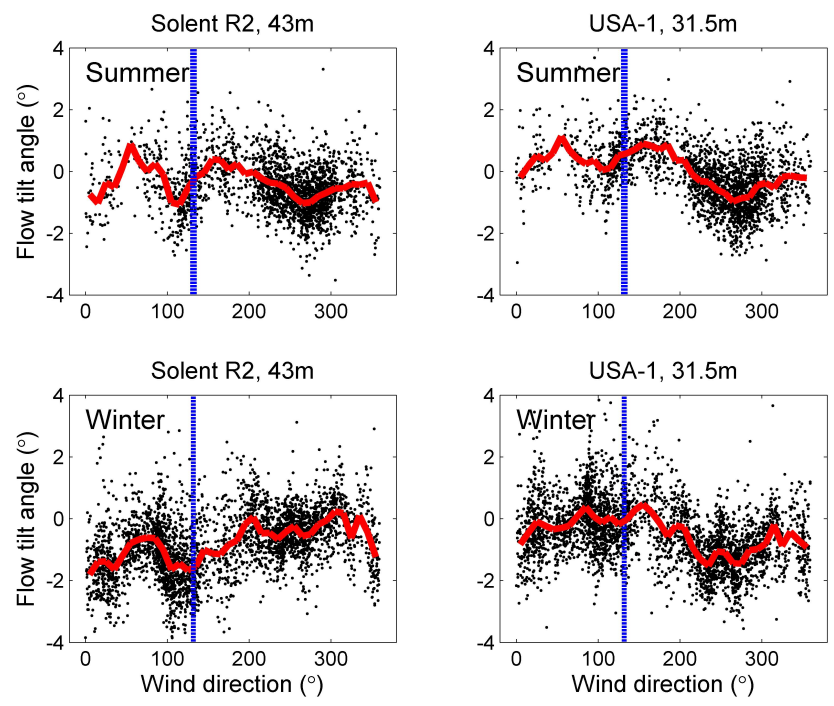

Fig. 5. Near-neutral dataset analysis of tilt angle during full leaf area index conditions (top) and low leaf area index conditions (bottom). The thick red line is the centered bin averages for each $10^{\circ}$ interval and the black dots correspond to the 30 min mean values. The vertical dashed line indicates the direction of the mast from the boom at $130^{\circ}$.

During the summer, the flow patterns measured by the two sonic anemometers were rather similar (Fig. 5, top), with a pronounced minimum of $-1^{\circ}$ to $-2^{\circ}$ around $270^{\circ}$, a less pronounced minimum around $110^{\circ}$ and weak maxima around $60^{\circ}$ and $160^{\circ}$. The flow angles from the Solent R2 were slightly lower than the USA- 1 data in the interval $\left[330^{\circ}\right.$, $100^{\circ}$ ]. This difference could be due to a small relative misalignment between the sonic anemometers, a physical effect caused by the different measurement heights or instrumental errors. The possibility of a relative misalignment is explored below.

The good agreement between the directional flow pattern from the two sonic anemometers disappeared during the winter period (Fig. 5, bottom). Whereas the main features from the summer were preserved for the USA-1, the Solent R2 sonic flow pattern was changed with more negative flow angles in the northeast and less negative flow angles in the southwest. Flow angles from both sonic anemometers showed a more variable pattern, with many local maxima and minima. Despite some similarities in mean response to wind direction, the squared correlation coefficient $\left(R^{2}\right)$ for nearneutral $W$ from the two sonic anemometers was only 0.39 for the summer period and 0.07 for the winter period. By applying a $1^{\circ}$ amplitude sine-curve tilt to the Solent $\mathrm{R} 2, R^{2}$ between the two sonic anemometers was improved to 0.54 for the summer period and 0.45 for the winter period.

In order to evaluate the effect of atmospheric stratification, the analysis was extended for the summer case to include the unstable and the stable datasets. The scatter for the halfhourly samples was evaluated for the $\left[250^{\circ}, 280^{\circ}\right]$ interval to 
$\sigma_{\alpha_{n}}=0.7^{\circ}, \sigma_{\alpha_{s}}=0.6^{\circ}$ and $\sigma_{\alpha_{u s}}=2.0^{\circ}$, where subscripts $n, s$ and $u s$ denote the neutral, stable and unstable subset respectively. By widening the interval to $\left[240^{\circ}, 290^{\circ}\right], \sigma_{\alpha_{u s}}$ was reduced to $1.6^{\circ}$.

Relative to the near-neutral data, the flow angles from the Solent R2 in the interval $\left[200^{\circ}, 270^{\circ}\right]$ during stable conditions were predominantly slightly more negative or slightly more positive, depending on whether the "corr 1" or "corr 2" flow distortion correction was applied. Similar tendencies for the difference between the near-neutral and stable subset could be observed also for other wind directions.

\subsection{Interpretation of flow angles in relation to the terrain}

Because of instrumental, statistical and alignment errors, the interpretation of flow angles in relation to upstream and downstream edges and the presented conceptual model (Fig. 1) is very uncertain. Some interpretation is nevertheless attempted and in Fig. 6, the binned averaged points for the $10^{\circ}$ intervals are shown. For the summer data (left), the local maxima around $60^{\circ}$ and $160^{\circ}$ could be related to the acceleration or deceleration phases for features 1 and 3 defined in Fig. 2. This would mean that the deceleration phase (Fig. 1), extends to at least $8 h_{C}$ during summer time for the height range of 31.5 to $43 \mathrm{~m}$.

As mentioned above, the sonic anemometers were probably misaligned relative to each other and a $1^{\circ}$ degree amplitude sine-curve tilt of either sonics would improve the agreement between the curves, especially during winter time. However, it is not possible to determine for which of the anemometers the tilt should be applied. Even without any extra tilt, some local maxima and minima agree well, also for the winter period.

In Fig. 6 (right), the results by the conically scanning ZephIR lidar (Dellwik et al., 2010b) are also included. Since the lidar measurements are not biased by temperaturedependent off-sets, flow distortion or significant vertical misalignment, we consider the data from the lidar more accurate than the sonic anemometers. Unfortunately, the experiment was too limited in time to provide tilt angle estimates for the whole $\left[0^{\circ}, 360^{\circ}\right]$ direction interval. The positive flow angles at $48 \mathrm{~m}$ indicate a slightly decelerating flow, most likely due to a deceleration phase (Fig.1).

\section{Discussion}

\subsection{Instrumental bias}

Given the reported effects of flow distortion (which may be dependent on wind speed) and the temperature dependence of transducers in Sect. 2, one can not expect the sonic anemometers to perfectly measure mean flow tilt angles and vertical velocities. Disregarding alignment problems and statistical uncertainty, we estimate that the sonic anemometer
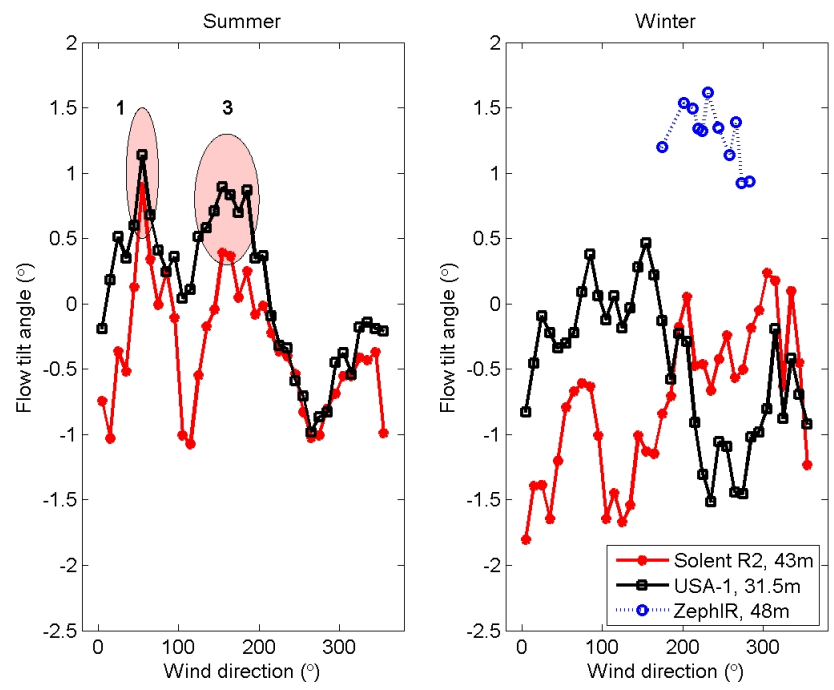

Fig. 6. Comparison of directional responses for the two sonic anemometers during summer (left) and winter (right). The result from the ZephIR lidar measured during the winter of 2006 (Dellwik et al., 2010b) at $48 \mathrm{~m}$ is also shown. The numbers at the ovals indicate an influence from an upstream or downstream forest edge, where the numbers refer to the listed features in Fig. 2.

tilt angles were not measured more accurately than $1^{\circ}-2^{\circ}$ over the forest. This estimate is based on the large effect of the presented incomplete flow distortion corrections (discussed below), as well as limited agreement between the lidar and anemometry data in Fig. 6. For the presented data, this translates to a mean vertical velocity error in the range of 2-20 $\mathrm{cm} \mathrm{s}^{-1}$, depending on wind speed and stratification, which is far from the $1 \mathrm{~mm} \mathrm{~s}^{-1}$ precision limit mentioned by Leuning et al. (2008). In comparison, the systematic error on the lidar data due to the inhomogeneity of the flow was estimated to be less than $0.2^{\circ}$ (Dellwik et al., 2010b).

Since the attack angle distribution (Fig. 3) is asymmetric with steeper attack angles for updrafts than for downdrafts, flow distortion corrections (also for vertically symmetrical instrumental designs) should be expected to have an effect on the mean vertical velocity and flow tilt angles. As shown in Fig. 4, this is indeed the case for the analyzed datasets, where the effect of the flow distortion correction is between $-150 \%$ and $-200 \%$ for the Solent R2 and between $50 \%$ and $75 \%$ for the USA-1. An obvious conclusion is that $W$ is very sensitive to flow distortion corrections.

However, both the applied flow distortion corrections have their limitations and can not be considered perfect; whereas the flow distortion correction supplied by Metek $\mathrm{GmbH}$ for the USA-1 does not cover the whole $\left[-90^{\circ}, 90^{\circ}\right]$ interval in the vertical, the flow distortion correction applied for the Solent R2 was based on measurements of only a $\left[0^{\circ}, 60^{\circ}\right]$ azimuthal interval, and symmetry arguments were used to make the $\left[0^{\circ}, 360^{\circ}\right]$ corrections. Further, the published correction (van der Molen et al., 2004) was an average over the $\left[0^{\circ}, 60^{\circ}\right]$ 
interval, meaning that any azimuthal effects of the struts and the transducers was assumed to be independent of the vertical attack angle. To achieve perfect correction of flow distortion, it is also necessary that the flow distortion for near-horizontal flow be correctly taken into account in the calibration by the manufacturer. However, for a Solent R2 anemometer, Grelle and Lindroth (1994) found that applying the flow distortion correction by Gill, flow distortion was increased instead of corrected, so for at least for some instruments, this is not true.

Högström and Smedman (2004) found that there was considerable difference between the flow distortion corrections for the individual Solent R2 and R3 instruments, which would question the idea of applying corrections from a different anemometer as done in this study. Nevertheless, the arguments for using the calibration are still strong, given the very large flow distortion errors from steep attack angles reported by van der Molen et al. (2004). Even if deviations exist between the individual Solent anemometers, the correction by van der Molen et al. (2004) represents the first and only attempt at correcting for the high attack angles where the transducers and supporting rod directly block the flow and this effect should be the representative for all instruments.

Another argument for not using the extended flow distortion correction provided by van der Molen et al. (2004) is that the relatively rare occurrence of high attack angles outside the $\left[-30^{\circ}, 30^{\circ}\right]$ would not considerably change the estimate of $W$. We tested this argument by excluding all attack angles greater than $\pm 30^{\circ}$ and found that the mean vertical velocity changed about $0.06 \mathrm{~ms}^{-1}$ for the near-neutral subset of data, $0.07 \mathrm{~ms}^{-1}$ for unstable and $0.01 \mathrm{~ms}^{-1}$ for the stable subset, i.e. the same order of magnitude as the signal itself. Hence, over rough surfaces like forests, the attack angle interval outside $\pm 30^{\circ}$ should not be ignored for future flow distortion corrections.

In most published studies on vertical advection, $W$ is taken as the difference between flow angles during near-neutral (or all stratifications) and stable stratification. This is very problematic given the possible temperature- and wind speed dependency of the flow distortion. Also, since the attack angle distribution on the sonic anemometer is a function of the atmospheric stratification as shown in Fig. 3, even without wind speed and temperature effects, the flow distortion is a function of the stratification. Instrumental uncertainties due to flow distortion can therefore not - unless the flow distortion correction scheme is absolutely perfect - be easily removed by assuming that the neutral data defines the zeroflow angle surface.

\subsection{Statistical uncertainty}

The statistical uncertainty on the flow angle using the integral time scale (Table 2) agreed qualitatively well with the standard deviation of the measured mean flow tilt angles in the $\left[250^{\circ}, 280^{\circ}\right]$ interval (Sect. 5.3), but the scatter in the measured flow tilt angles was generally higher.

The high statistical uncertainty was also reflected in the presented analysis by the relatively low correlation between the half-hourly mean values of $W$ by the USA- 1 and Solent $R 2\left(R^{2} \approx 0.5\right.$ for both summer and winter data after the Solent R2 was corrected for misalignment). Since the USA1 and R2 in this study were located $12 \mathrm{~m}$ apart in the vertical direction, and the vertical fluctuations have limited horizontal and vertical extent, this could explain the low correlation. Because of flow distortion errors, it is also to be expected that vertical velocities measured with sonic anemometers from different manufacturers would give a lower correlation than two anemometers by the same manufacturer. However, Heinesch et al. (2007) also found a correlation of only 0.5 for measurements taken only $2 \mathrm{~m}$ apart by a Solent R3 and a R2.

One consequence of the high statistical uncertainty of $W$ is the high scatter of the vertical advection term as reported by e.g. Feigenwinter et al. (2008). In order to reduce the statistical uncertainty of $W$ to detect larger-scale motions of magnitude as low as $1 \mathrm{~mm} \mathrm{~s}^{-1}$, stationary time series of 10100 days duration would be necessary.

The statistical uncertainty on a 30 minute average of flow tilt angle is also evaluated to $\approx 1^{\circ}$ with lower uncertainty for stable flow and higher for unstable.

\subsection{Flow tilt angles downstream of forest edges}

Despite the estimated low accuracy of the sonic anemometers, it seems clear from Fig. 6 that the flow at the Sorø site does not follow the terrain. Positive flow angles were distinguished for the wind directions with the shortest distances to upstream forest edges and the lidar data also pointed to positive flow angles during winter time for the directions where the fetch was $17 h_{C}$ and homogeneous. This feature could be coupled to a decelerating or acceleration flow as shown in Fig. 1. A decelerating flow due to an upwind roughness shift is also a feature of the Internal Boundary Layer, and the presented results are in accordance with earlier IBL studies at the Sorø site (Dellwik and Jensen, 2005; Mammarella et al., 2008).

In the presence of forest edges, there are several possible explanations for why the tilt angles may vary with stratification. For example, a difference may be caused by different internal boundary growth rates as a function of stratification (Rao, 1975), or by varying Froude number affecting the directional shift at the forest edge, or by different effects of the leaf area index distribution at varying atmospheric stratification. These effects are quite different from the effects suggested by Lee (1998) in that they are dependent on local factors rather than larger-scale phenomena.

In order to measure the real tilt angles in relation to the terrain, the uncertainty regarding vertical alignment should be added to the instrumental uncertainty. We estimate that 
error to be $1^{\circ}-2^{\circ}$, which is similar to the instrumental uncertainty. Provided that the instrument geometry is not bent, vertical alignment could be assessed and improved by use of an inclinometer, which significantly would reduce this error source. Alignment errors can also be avoided using Doppler lidars (Dellwik et al., 2010b).

\subsection{Implications for vertical advection estimates at fetch-limited sites and sites with clearings}

Since the flow is not parallel to the terrain at the Sorø site, a control volume (such as the one defined by Leuning et al., 2008) will generally have a component of vertical advection either increasing or decreasing the scalar concentration in the volume. If systematic vertical advection caused by flow adaption to forest edges should be included in the carbon budget of the surface, advection flows would be of greater importance than previously estimated. To illustrate this, we have calculated the vertical advection term based on the presented results for near-neutral flow. For these data, we can assume that the canopy-layer of the forest is relatively wellmixed and the measured carbon dioxide profile representative for a larger area than during the lower wind conditions of non-neutral stratification.

For the summer data, both sonic anemometers showed a well-defined minimum around $270^{\circ}$, which corresponds to the wind direction of a homogeneous fetch for approximately $500 \mathrm{~m}$. Turbulent carbon dioxide flux data at near-neutral conditions from the direction interval $\left[250^{\circ}, 280^{\circ}\right]$ and carbon dioxide profile data from the summer of 2007 were used to assess the potential effect of systematic advection. The advection term was evaluated following Lee (1998) as

$$
\int_{0}^{z_{m}} W(z) \frac{\partial C}{\partial z} d z=W_{z_{m}}\left(C_{z_{m}}-z_{m}^{-1} \int_{0}^{z_{m}} C(z) d z\right)
$$

For $C(z)$ a piecewise constant measured values of the $\mathrm{CO}_{2}$ gradient was used in the integration.

In Fig. 7, the mean diurnal course of the estimated fluxes from the $43 \mathrm{~m}$ level are presented. A positive mean flow tilt angle of $1^{\circ}$ reduces the diurnal variation significantly, whereas a negative mean flow tilt angle will enhance the diurnal variation.

A common argument for not including the large vertical advection term, is that the horizontal advection term would balance out the vertical advection leading to a near-zero advection contribution (Feigenwinter et al., 2004; Aubinet et al., 2005). This argument is particularly relevant for the presented site, since we see a local forest edge effect on $W$ and this local effect would presumably also cause changes to other terms in the scalar conservation equation. A large horizontal advection term of opposite sign as the vertical advection near a forest edge was modeled by Sogachev et al. (2008). To attempt a complete measurement of all the terms in the equation, as done by Leuning et al. (2008), would

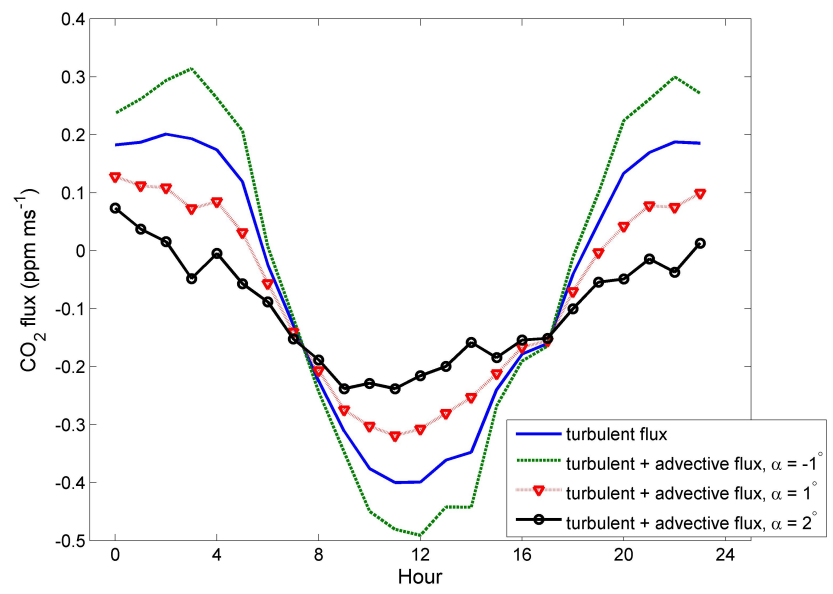

Fig. 7. Rough estimate of the vertical advection flux component in relation to the turbulent flux for tilt angles of $-1^{\circ}, 1^{\circ}$ and $2^{\circ}$ at a mean wind speed of $4 \mathrm{~ms}^{-1}$ for carbon dioxide profile measurements from the $\left[250^{\circ}, 280^{\circ}\right]$ wind direction interval.

however not be sensible unless the instrumental errors were considerably reduced.

\section{Conclusions}

An analysis of mean vertical velocities and flow tilt angles from 3-D sonic anemometers was presented. For the sonic anemometers (Solent Gill R2 and Metek USA-1), flow distortion correction schemes were applied to account for how the sonic structure affects the measured flow. It was found that the flow distortion correction is uncertain and affects the mean flow angles significantly. For the Solent R2, the mean value of the vertical velocity during all types of stratification and wind directions changed from being positive to negative. The corrections were dependent on the attack angle distribution on the sonic anemometer, which varies with atmospheric stratification. As a result, the uncertainty associated with the flow distortion varies with the atmospheric stratification.

The statistical uncertainty of the 30 min mean vertical velocities was estimated using sonic anemometer data and was found to be of similar magnitude as the expected mean values of the vertical velocity. The estimated statistical uncertainty agreed qualitatively well with the actual scatter of halfhourly averages of measured flow angles.

Since the forest site is fetch-limited and contains clearings, non-zero flow angles were expected even during neutral atmospheric stratification. The dependence of the measured flow angle on wind direction was therefore analyzed. Instead of using a tilt-rotation algorithm where flow angles were assumed to be zero for neutral conditions, as has been done in most vertical advection studies, the coordinate system defined by the sonic anemometers were used. 
Both positive and negative flow angles were found, but the sonic anemometer data did not agree with the results of the lidar measurements presented in Dellwik et al. (2010b). Since the lidar data is not affected by flow distortion, significant vertical misalignment and temperature dependent offsets, the accuracy of the lidar is considerably better than for the sonic anemometers. Generally, mean vertical velocities and flow angles from the sonic anemometers are therefore considered uncertain and beyond the limit of what can be measured experimentally.

The vertical advection term based on a single point measurement was estimated for the western sector of the forest. However, it was not recommended to include this term the flux calculation, unless (1) all terms in the scalar conservation equation are evaluated and (2) the instrumental accuracy for measuring $W$ is improved, for example by using a Doppler lidar.

Acknowledgements. The authors would like to acknowledge Søren Larsen, Niels Otto Jensen (at the Wind Energy Division at Ris $\varnothing$-DTU) and Gunnar Schade (at the Department for Atmospheric Sciences, Texas A\&M University) for valuable comments on the manuscript. This work is financed through the NECC project funded by the Nordic Natural Science Research Councils (NOS-N), and the Forest and Wind Profiles project funded by the Danish Strategic Research Council.

Edited by: A. Lindroth

\section{References}

Aubinet, M., Berbigier, P., Bernhofer, C., Cescatti, A., Feigenwinter, C., Granier, A., Grunewald, T., Havrankova, K., Heinesch, B., Longdoz, B., Marcolla, B., Montagnani, L., and Sedlak, P.: Comparing $\mathrm{CO}_{2}$ storage and advection conditions at night at different CarboEuroflux sites, Bound.-Lay. Meteorol., 116, 63-94, 2005.

Baldocchi, D., Finnigan, J., Wilson, K., Paw, U. K., and Falge, E.: On measuring net ecosystem exchange over tall vegetation on complex terrain, Bound.-Lay. Meteorol., 96, 257-291, 2000.

Baldocchi, D., Falge, E., Gu, L., Ohlson, R., Hollinger, D., Running, S., Anthoni, P., Bernhofer, C., Davis, K., Evans, R., Fuentes, J., Goldstein, A., Katul, G., Law, B., Lee, X., Malhi, Y., Meyers, T., Munger, W., Oechel, W., Paw, U. K., Pilegaard, K., Schmid, H., Valentini, R., Verma, S., Vesala, T., Wilson, K., and Wofsy, S.: FLUXNET: A new tool to study the temporal and spatial variability of ecosystem-scale carbon dioxide, water vapor and energy flux densities, B. Am. Meteorol. Soc., 82, 2415-2434, 2001.

Belcher, S. and Hunt, J.: Turbulent flows over hills and waves, Ann. Rev. Fluid Mech., 30, 507-538, 1998.

Belcher, S., Jerram, N., and Hunt, J.: Adjustment of a turbulent boundary layer to a canopy of roughness elements, J. Fluid Mech., 488, 369-398, 2003.

Belcher, S., Finnigan, J., and Harman, I.: Flows through forest canopies in complex terrain, Ecol. Appl., 18, 1436-1453, 2008.
Cassiani, M., Katul, G., and Albertson, J.: The effects of canopy leaf area index on airflow across forest edges: large-eddy simulation and analytical results, Bound.-Lay. Meteorol., 126, 433460, 2008.

Dellwik, E. and Jensen, N.: Internal equilibrium layer growth over forest, Theor. Appl. Climatol., 66, 173-184, 2000.

Dellwik, E. and Jensen, N.: Flux-profile relationships for a fetch limited beech forest, Bound.-Lay. Meteorol., 115, 179-204, 2005.

Dellwik, E., Mann, J., and Bingöl, F.: Flow tilt angles near forest edges - Part 2: Lidar anemometry, Biogeosciences, 7, 17591768, doi:10.5194/bg-7-1759-2010, 2010.

Dupont, S. and Brunet, Y.: Edge flow and Canopy Structure, Bound.-Lay. Meteorol., 126, 51-71W, 2008.

Feigenwinter, C., Bernhofer, C., and Vogt, R.: The influence of advection on the short term $\mathrm{CO}_{2}$ budget in and above a forest canopy, Bound.-Lay. Meteorol., 113, 201-224, 2004.

Feigenwinter, C., Bernhofer, C., Eichelmann, U., Heinesch, B., Hertel, M., Janous, D., Kolle, O., Lagergren, F., Lindroth, A., Minerbi, S., Moderow, U., Mölder, M., Montagnani, L., Queck, R., Rebmann, C., Vestin, P., Yernaux, M., Zeri, M., Ziegler, W., and Aubinet, M.: The influence of advection on the short term $\mathrm{CO}_{2}$ budget in and above a forest canopy, Agr. Forest Meteorol., 148, 12-24, 2008.

Finnigan, J.: A comment on the paper by Lee (1998): On micrometeorological observations of surface-air exchange over tall vegetation, Agr. Forest Meteorol., 97, 55-64, 1999.

Gash, J. and Dolman, A.: Sonic anemometer (co)sine response and flux measurement I. The potential for (co)sine error to affect sonic anemometer-based flux measurements, Agr. Forest Meteorol., 119, 195-207, 2003.

Grelle, A. and Lindroth, A.: Flow distortion by a Solent sonic anemometer: Wind tunnel calibration and its Assessment for flux measurements over forest and field, J. Atmos. Ocean. Tech., 11, 1529-1542, 1994.

Heinesch, B., Yernaux, M., and Aubinet, M.: Some methodological questions concerning advection measurements: a case study, Bound.-Lay. Meteorol., 122, 457-478, 2007.

Högström, U. and Smedman, A.-S.: Accurace of sonic anemometers: laminar wind-tunnel calibrations compared to atmospheric in-situ calibrations against a reference instrument, Bound.-Lay. Meteorol., 111, 33-54, 2004.

Irvine, M., Gardiner, B., and Hill, M.: The evolution of turbulence across a forest edge, Bound.-Lay. Meteorol., 84, 467-496, 1997.

Kutsch, W., Kolle, O., Rebmann, C., Knohl, A., Ziegler, W., and Schulze, E.-D.: Advection and resulting $\mathrm{CO}_{2}$ exchange uncertainty in a tall forest in central Germany, Ecol. Appl., 18, 13911405, 2008.

Lee, X.: On micormeteorological observations of surface-air exchange over tall vegetation, Agr. Forest Meteorol., 91, 39-49, 1998.

Lenschow, D. H., Mann, J., and Kristensen, L.: How Long Is Long Enough When Measuring Fluxes and Other Turbulence Statistics?, J. Atmos. Ocean. Tech., 11, 661-673, 1994.

Leuning, R., Zegelin, S., Jones, K., Keith, H., and Hughes, D.: Measurement of horizontal and vertical advection of $\mathrm{CO}_{2}$ within a forest canopy, Agr. Forest Meteorol., 148, 1777-1797, 2008. 
Mammarella, I., Kolari, P., Rinne, J., Keronen, P., and Vesala, T.: Determining the contribution of vertical advection to the net ecosystem exchange at Hyytiala forest, Finland, Tellus B, 59, 900-909, 2007.

Mammarella, I., Dellwik, E., and Jensen, N.: Turbulence spectra, shear-stress and tubulent kinetic energy budgets above two beech forest sites in Denmark, Tellus B, 60, 179-187, 2008.

McMillen, R.: An eddy correlation technique with extended applicability to non-simple terrain, Bound.-Lay. Meteorol., 43, 231245, 1988.

Morse, A., Gardiner, B., and Marshall, B.: Mechanisms controlling turbulence development across a forest edge, Bound.-Lay. Meteorol., 103, 227-251, 2002.

Nakai, T., van der Molen, M., Gash, J., and Kodama, Y.: Correction of sonic anemometer angle of attack errors, Agr. Forest Meteorol., 136, 19-30, 2006.

Panofsky, H. and Dutton, J.: Atmospheric turbulence, Wiley (Interscience), 397 pp., 1984.

Paw U., K. T., Baldocchi, D., Meyers, T., and Wilson, K.: Correction of eddy-covariance measurements incorporating both advective effects and density fluxes, Bound.-Lay. Meteorol., 97, 487$511,2000$.

Pilegaard, K., Mikkelsen, T., Beier, C., Jensen, N., Ambus, P., and Ro-Poulsen, H.: Field measurements of atmosphere-biosphere interactions in a Danish beech forest, Boreal Environ. Res., 8, 315-333, 2003.

Rao, K.: Effetct of thermal stratification on the growth of the internal boundary layer, Bound.-Lay. Meteorol., 8, 227-234, 1975.
Smith, F., Carson, D., and Oliver, H.: Mean wind direction shear through a forest canopy, Bound.-Lay. Meteorol., 3, 178-190, 1972.

Sogachev, A., Rannik, Ü., and Vesala, T.: Flux footprint over complx terrain covered by heterogeneous forest., Agr. Forest Meteorol., 127, 143-158, 2004.

Sogachev, A., Leclerc, M., Zhang, G., Rannik, U., and Vesala, T.: $\mathrm{CO}_{2}$ fluxes near a forest edge: a numerical study, Ecol. Appl., 18, 1454-1469, 2008.

Thom, A.: Momentum absorption by vegetation, Q. J. Roy. Meteorol. Soc., 97, 414-428, 1971.

van der Molen, M., Gash, J., and Elbers, J.: Sonic anemometer (co)sine response and flux measurement II. The effect of introducing an angle of attack dependent calibration, Agr. Forest Meteorol., 112, 95-109, 2004.

Vickers, D. and Mahrt, L.: Contrasting mean vertical motion from tilt correction methods and mass coninuity, Agr. Forest Meteorol., 138, 93-103, 2006.

Wilczak, J., Oncley, S., and Stage, S.: Sonic anemometer tilt corrections algorithms, Bound.-Lay. Meteorol., 99, 127-150, 2001.

Yang, B., Raupach, M., Shaw, R., U, K., and Morse, A.: Large-eddy simulation of turbulent flow across a forest edge. Part1: Flow statistics, Bound.-Lay. Meteorol., 120, 377-412, 2006.

Yi, C., Anderson, D., Turnipseed, A., Burns, S., Sparks, J., Stannard, D., and Monsoon, R.: The contribution of advective fluxes to net ecosystem exchange in a high-elevation, subalpine forest, Ecol. Appl., 18, 1379-1390, 2008. 